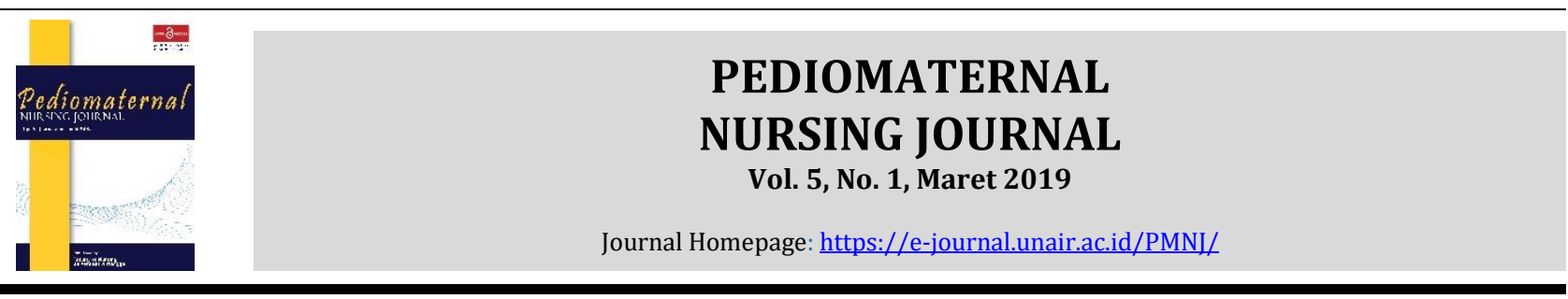

Original Research

\title{
Hubungan Pola Asuh Orang Tua dengan Perkembangan Anak Usia Prasekolah di TK RA Cut Nyak Dien
}

\author{
(Relationship between Parenting Styles and the Development of Preschoolers at TK RA Cut Nyak \\ Dien)
}

\author{
Ketjuk Herminaju dan Ratna Kholidati \\ STIKes Hutama Abdi Husada Tulungagung, Jawa Timur, Indonesia
}

ARTICLE HISTORY
Received: March 17, 2019
Accepted: May 27, 2019
KEYWORDS
parenting styles; child
development; preschool
CoRRESPONDING AUTHOR
Ketjuk Herminaju
berlian.ysaputri@gmail.com
STIKes Hutama Abdi Husada
Tulungagung, Jawa Timur,
Indonesia

Cite this as:

\begin{abstract}
Introduction: Development is a progressive which means irreversible, development that is movement, language, social and independence. The age of preschoolers can be ordered as a golden period or golden age, an important period in development. In this period parents' parenting is very important. But parents sometimes do not pay attention to parenting who is good, they are always worried about what if left alone. Therefore parents must know the importance of having good parenting. The purpose of this study was to study the pattern of foster care of parents with the development of preschool children.
\end{abstract}

Methods: Pre correlational with cross sectional method. Population of all parents and preschoolers at RA Kindergarten. Cut Nyak Dien in Gendingan Kedungwaru Village for 6 08 February 2018 as many as 72 . The samples of this study were 72 parents and preschool children who met the inclusion and exclusion criteria. Total sampling technique, questionnaire and KPSP instruments, and spearman rank ranking statistics ( rho) with $\alpha=$ 0.05 .

Results: The study obtained $63(87.5 \%)$ parents who had authoritative parenting and with appropriate child development as many as $65(90.3 \%)$ while authoritarian parenting with a number of $1(1.4 \%)$. spearman rank (rho) with a value of $\mathrm{P}=0,000<\alpha(0,05)$, then there is a relationship between Parenting Parenting and the Development of Preschool children in TK RA. Cut Nyak Dien Gendingan village Kedungwaru.

Conclusion: Parenting Parenting has a relationship to the development of preschool children. Where parents who have authoritative parenting, the development of children in accordance with the development.

Herminaju, K., \& Kholidati, R. (2019). Hubungan Pola Asuh Orang Tua dengan Perkembangan Anak Usia Prasekolah di TK RA Cut Nyak Dien. Pediomaternal Nurs. J., 5(1), 119-123.

\section{PENDAHULUAN}

Dalam upaya pembangunan manusia yang berkualitas, faktor perkembangan anak juga mendapat perhatian khusus dari pemerintah. Tumbuh- kembang anak harus berjalan sejajar agar dapat menghasilkan insan pembangunan yang mandiri dan bertanggung jawab (1). Masa pra sekolah (3 - 6 tahun) adalah periode penting dalam tumbuh kembang, karena merupakan pertumbuhan dasar yang akan mempengaruhi perkembangan anak selanjutnya.Pada masa prasekolah perkembangan bahasa, kreatifitas, sosial, emosional dan intelegansi berjalan sangat cepat (2). Masa prasekolah di sebut juga "masa keemasan" (golden periode) dan tidak berlangsung lama, sehingga anak harus mendapatkan perhatian yang serius. Perkembangan moral serta dasar kepribadian juga dibentuk pada masa ini, sehingga setiap kelainan penyimpangan sekecil apapun apabila tidak terdeteksi apalagi tidak ditangani dengan baik akan mengurangi kualitas sumber daya manusia kelak kemudian hari (3).

Di Indonesia sendiri banyak dijumpai gangguan pertumbuhan dan perkembangan anak. Pada tahun 2005 di Rumah Sakit Umum Dr. Soetomo di Surabaya, dijumpai sebanyak 323 anak yang mengalami 
gangguan perkembangan yang dapat diuraikan sebagai berikut gangguan berbahasa terdapat 190 kasus, gangguan perkembangan motorik kasar, motorik halus maupun sosial didapati 133 kasus (4). Dibandingkan dengan negara barat perkembangan motorik kasar anak Indonesia masih tergolong lambat. Di Amerika Serikat, anak mulai berjalan pada umur 11-12 bulan dan di Eropa antara 12-13 bulan, sedangkan di Indonesia rata-rata 14 bulan. Salah satu penyebab perbedaan tersebut adalah rendahnya kemampuan orang tua dalam mengasuh perkembangan motorik kasar, motorik halus, bahasa dan sosial sehingga rangsangan atau stimulus pada anak kurang optimal (5).

Berdasarkan survei pendahuluan yang dilakukan peneliti di Lembaga Pendidikan Taman Kanak-Kanak RA Cut Nyak Dien Kota Tulungagung anak usia prasekolah seharusnya memiliki kebutuhan dasar emosional untuk bersosialisasi dengan anak-anak lainnya, tetapi ada 7 anak dari 32 anak (21,8 \%) yang belum bisa bersosialisasi dengan anak-anak lainnya dan masih ketergantungan pada orang tua. Ketergantungan anak yang berlebihan pada orang tua akan berpengaruh buruk terhadap perkembangan sosial anak. Dimana anak akan sangat bergantung pada orang tua atau ibunya. Sehingga didalam kehidupannya, jika anak membutuhkan sesuatu, maka anak akan lebih cenderung memilih orang tua atau ibunya untuk membantunya. Dampaknya anak cenderung kurang matang secara sosial atau tidak dapat bersosialisasi dengan orang lain dan mengalami keterlambatan perkembangan (6).

Pendampingan orang tua sangat diperlukan. Hal ini merupakan cara orang tua dalam mendidik agar anak menjadi seorang yang dicita-citakan yang tentunya lebih baik dari orang tuanya. Cara orang tua mendidik anaknya disebut sebagai pola pengasuhan. Sehingga orang tua harus bisa menentukan pola asuh yang tepat sesuai perkembangan anak. Kategori pola asuh menjadi tiga jenis, yaitu: pola asuh permisif, otoriter dan otoritatif (7). Dampak pengasuhan orang tua akan berbeda terhadap perkembangan anak. Melalui pengasuhan orang tua, terutama orang tua yang otoritatif, anak diharapkan dapat mengembangkan perkembangan dengan baik.

Pola pengasuhan otoritatif sangat mendukung perkembangan pada anak, sedangkan dua pengasuhan lainnya bersifat kurang mendukung. Untuk dapat membentuk perkembangan yang baik pada anak, orang tua harus meningkatkan sifat positif, memberikan semangat dan dorongan kepada anaknya agar menggali potensi dan kemampuan diri dengan memberikan banyak kegiatan positif agar belajar mandiri yang pada akhirnya dapat hidup bermasyarakat dengan baik. Sedangkan salah satu peran perawat adalah sebagai pendidik. Oleh karena itu, perawat perlu memaksimalkan perannya sebagai pendidik dengan memberikan pendidikan kepada orang tua tentang pentingnya penerapan pola asuh yang tepat untuk membangun perkembangan anak. Dari uraian diatas maka penulis ingin meneliti "Hubungan Pola Asuh Orang Tua Dengan
Perkembangan Anak Usia Prasekolah Di TK RA Cut Nyak Dien Desa Gendingan Kecamatan Kedungwaru Kabupaten Tulungagung Tahun 2018”.

\section{METODE}

\subsection{Desain}

Jenis penelitian yang digunakan dalam penelitian ini adalah study correlational dengan pendekatan cross sectional.

\subsection{Populasi, sampel, dan sampling}

Populasi dari penelitian ini adalah Semua orang tua dan anak - anak Di TK RA Cut Nyak Dien Ds. Gendingan Kecamatan Kedungwaru Tulungagung yang berjumlah 72 responden. Sampel dari penelitian ini adalah Semua orang tua dan anak-anak Di TK RA Tjut Njiak Dien Desa Gendingan Kecamatan Kedungwaru Tulungagung yang berjumlah 72 responden yang memenuhi kriteria inklusi. Pada penelitian ini teknik pengambilan sampel secara total sampling. Kriteria inklusi dalam penelitian ini adalah semua siswa dan orang tua yang hadir di sekolah pada saat penelitian laksanakan, sedangkan kriteria ekslusi dalam penelitian ini adalah siswa yang tidak hadir saat pelaksanaan penelitian, siswa yang tidak di dampingi orang tuanya pada saat penelitian.

\subsection{Variabel}

Variabel independen dalam penelitian ini adalah pola asuh orang tua, sedangkan variable dependen adalah perkembangan anak usia prasekolah di tk ra. cut nyak dien desa gendingan kedungwaru tulungagung.

\subsection{Instrumen dan analisis data}

Dalam menganalisis Hubungan Pola Asuh Orang Tua Dengan Perkembangan Anak Usia Prasekolah Di TK RA Cut Nyak Dien Desa Gendingan Kecamatan Kedungwaru Kabupaten Tulungagung Tahun 2018, instrument yang digunakan untuk menilai pola asuh orang tua adalah kuesioner, sedangkan instrument yang digunakan untuk menilai perkembangan anak menggunakan kuesioner pra skrining perkembangan (KPSP) dimana item yang terdapat dalam kuesioner ini terdiri atas perkembangan motorik kasar, perkembangan motorik halus, perkembangan bahasa, perkembangan sosialisasi dan kemandirian. Sebelum kuesioner dibagikan kuesioner tersebut telah diuji validitas dan reliabilitasnya, hasil uji kuesioner menunjukkan kuesioner telah valid dan reliable. Uji statistic yang digunakan adalah spearman rho rank test. Bila $\rho$ value $<0,05$ dikatakan significant, yaitu hipotesis nol $\left(\mathrm{H}_{0}\right)$ ditolak, maka $\mathrm{H}_{1}$ diterima yang berarti menyatakan ada Hubungan Pola Asuh Orang Tua Dengan Perkembangan Anak Usia Prasekolah.Bila $\rho$ value $>0,05$ maka hipotesis nol diterima, dan $\mathrm{H}_{1}$ ditolak yang berarti menyatakan tidak ada Hubungan Pola Asuh Orang Tua Dengan Perkembangan Anak Usia Prasekolah. 


\section{Hasil}

Sebagian besar dari responden memiliki pola asuh otoritatif sebanyak 64 responden $(88,9 \%)$ dan pola asuh otoriter 1 reponden (1,4\%) [Tabel 1]. Sebagian besar perkembangan anak adalah sesuai dengan jumlah 65 anak $(90,3 \%)$ dan meragukan $2(2,8 \%)$ [Tabel 2]. Hampir seluruhnya mempunyai pola asuh otoritatif dengan perkembangan anak yang sesuai, yaitu sebanyak 63 responden 87,5\% sedangkan pola asuh otoriter sebanyak 1 responden $(1,4 \%)$ [Tabel 3]. antara orang tua dan anak. Sehingga model pola asuh yang seperti inilah yang sangat diharapkan di masyarakat. Untuk itu peneliti akan lebih lanjut menyampaikan model pola asuh ini kepada masyarakat agar tipe pola pengasuhan otoritatif bisa menjadi tradisi di setiap- setiap kususnya keluarga, masyarakat, dan negara.

\subsection{Perkembangan anak prasekolah di TK RA Cut} Nyak Dien

Berdasarkan hasil penelitian pada tabel tabulasi 72 responden didapatkan bahwa kriteria perkembangan

Tabel 1 Distribusi pola asuh orang tua $(\mathrm{n}=72)$

\begin{tabular}{cllcc}
\hline No & & Pola Asuh Orang Tua & n & \% \\
\hline 1 & Otoritatif & & 64 & 88,9 \\
2 & Otoriter & & 1 & 1,4 \\
3 & Permisif & \multirow{2}{*}{ Jumlah } & 7 & 9,7 \\
& & 72 & 100 \\
\hline
\end{tabular}

Tabel 2 Distribusi perkembangan anak $(\mathrm{n}=72)$

\begin{tabular}{|c|c|c|c|}
\hline No & Perkembangan Anak & $\mathbf{n}$ & $\%$ \\
\hline 1 & Sesuai & 65 & 90,3 \\
\hline 2 & Meragukan & 2 & 2,8 \\
\hline 3 & Penyimpangan & 5 & 6,9 \\
\hline & Jumlah & 72 & 100 \\
\hline
\end{tabular}

Tabel 3 Pola Asuh Orang Tua dengan Perkembangan Anak (n=72)

\begin{tabular}{lcccc}
\hline \multirow{2}{*}{$\begin{array}{c}\text { Pola Asuh Orang } \\
\text { Tua }\end{array}$} & \multicolumn{3}{c}{ Perkembangan Anak } & Total \\
\cline { 2 - 4 } & $\begin{array}{c}\text { Penyimpangan } \\
\mathrm{n}(\%)\end{array}$ & $\begin{array}{c}\text { Meragukan } \\
\mathrm{n}(\%)\end{array}$ & $\begin{array}{c}\text { Sesuai } \\
\mathrm{n}(\%)\end{array}$ & $\mathrm{n}(\%)$ \\
\hline Permisif & $5(6,9)$ & $1(1,4)$ & $1(1,4)$ & $7(9,7)$ \\
Otoriter & $0(0)$ & $0(0)$ & $1(1,4)$ & $1(1,4)$ \\
Otoritatif & $0(0)$ & $1(1,4)$ & $63(87,5)$ & $64(88,9)$ \\
Total & $5(6,9)$ & $2(2,8)$ & $65(90,3)$ & $72(100)$ \\
& Hasil uji statistik spearman rank $($ rho $) \mathrm{p}=0,00<\alpha=0,05$ & \\
\hline
\end{tabular}

\section{PEMBAHASAN}

4.1 Pola asuh orang tua pada anak prasekolah di TK RA Cut Nyak Dien

Memperhatikan hasil penelitian pada tabel 3 Pola Asuh Orang Tua di TK RA Cut Nyak Dien Ds.Gendingan Kecamatan Kedungwaru Kabupaten Tulungagung Tahun 2014/ 2018dari 72 responden menunjukan bahwa kriteria dengan pola asuh otoritatif sebanyak 64 responden $(88,9 \%)$, pola asuh otoriter sebanyak 1 responden $(1,4)$, dan pola asuh permisif sebanyak 7 responden $(9,7 \%)$.

Pola asuh otoritatif lebih dominan daripada pola asuh yang lain membuktikan bahwa terdapatnya hubungan yang harmonis antara anak dan orang tua sehingga tercipta saling pengertian dan keterbukaan. Anak bebas berekspresi dan mengemukakan kemauan serta pendapat mereka dengan terbuka (8).

Dengan diketemukannya metode pola asuh (otoritatif) diwilayah yang kami teliti, maka akan sangat besar harapan keluarga, masyarakat untuk terciptanya saling pengertian dan keterbukaan yang sesuai sebanyak 65 responden(90,3\%), meragukan sebanyak 2 responden (2,8\%), penyimpangan sebanyak 5 responden $(6,9 \%)$.

Perkembangan adalah bertambahnya struktur dan fungsi tubuh yang lebih komplek dalam kemampuan gerak kasar, gerak halus, bicara dan bahasa serta sosialasi dan kemandirian (9). Perkembangan adalah suatu proses yang kontinu, yang dimulai sejak anak dilahirkan. Kematangan sosial merupakan suatu evolusi perkembangan perilaku, dimana nantinya seorang anak dapat mengekspresikan pengalamannya secara utuh dan dia belajar secara bertahap untuk meningkatkan kemampuannya untuk mandiri, bekerja sama dengan orang lain dan bertanggung jawab terhadap kelompoknya (10).

Berdasarkan teori faktor - faktor yang mempengaruhi perkembangan (10), yaitu suasana rumah, pola asuh (cara mengasuh anak), dan lingkungan di luar rumah. Berdasarkan tabel 3 diketahui bahwa dari 72 responden hampir seluruh mempunyai pola asuh otoritatif dengan 
perkembangan yang sesuai, yaitu sebanyak 65 responden $87,4 \%$.

Hal ini bila dikaitkan dengan teori dari (Kim Paleg, 2004) yaitu pola asuh adalah cara atau proses mendidik agar kepribadian anak dapat berkembang dengan baik, ketika dewasa jadi bertanggung jawab. Pola asuh yang baik menjadikan anak berkepribadian kuat, tak mudah putus asa, dan tangguh menghadapi tekanan hidup.

Jadi mengacu pada teori serta fakta penelitian yang didapatkan menggambarkan bahwa perkembangan dipengaruhi oleh pola asuh orang tua yang sesuai dengan perkembangan anak. Oleh karenanya dari ketiga faktor yang berpengaruh tersebut haruslah seimbang dan harus mendapat perhatian yang serius dari orang tua.

\subsection{Hubungan pola asuh orang tua dengan} perkembangan anak prasekolah di TK RA Cut Nyak Dien

Berdasarkan tabel 3 hasil pengujian diketahui bahwa dari 72 responden hampir seluruhnya mempunyai pola asuh otoritatif dengan perkembangan anak yang sesuai, yaitu sebanyak 63 responden 87,5\% sedangkan pola asuh otoriter sebanyak 1 responden 1,4\%. Dari hasil uji statistik spearman rank (rho) diperoleh nilai signifikan $p=0,000<\alpha=0,05$ maka HO ditolak yang berarti ada hubungan pola asuh orang tua dengan perkembangan anak prasekolah.

Dengan hasil tersebut bila dikaitkan dengan teori yang ada, bahwa semakin baik pola asuh orang tua (otoritatif) kepada anaknya, maka perkembangan anak akan semakin baik (sesuai). Penelitian ini sejalan dengan teori (11). Orang tua yang memiliki karakteristik sikap outoritatif memperlakukan anak sesuai dengan tahapan perkembangan usia anak dan memperhatikan serta mempertimbangkan keinginan-keinginan anak (12).

Dari hasil penelitian yang dilakukan (13) menyatakan bahwa hasil penelitian yang dilakukan menunjukkan bahwa pola asuh otoritatif lebih dipilih orang tua karena mereka mulai mengetahui dan menyadari bahwa pola pengasuhan ini merupakan yang paling efektif bagi perkembangan anak. Pada pola pengasuhan otoritatif, orang tua mendorong anak untuk menjadi mandiri tetapi tetap memberikan batasan serta mengontrol perilaku anak.

Didapatkan orang tua mempunyai pola asuh otoritatif akan mempunyai anak dengan perkembangan yang sesuai, hal ini membuktikan betapa pentingnya pola asuh orang tua terhadap perkembangan anak. Pola asuh otoritatif adalah pola pengasuhan yang cocok dan baik untuk diterapkan para orang tua kepada anak-anaknya. Anak yang diasuh dengan tehnik asuhan otoritatif akan hidup ceria, menyenangkan, kreatif, cerdas, percaya diri, terbuka pada orang tua, menghargai dan menghormati orang tua, tidak mudah stres dan depresi, berprestasi baik, disukai lingkungan dan masyarakat lainnya (14).

Dalam penelitian ini didapatkan orang tua yang mempunyai pola asuh otoritatif juga mempunyai anak dengan perkembangannya sesuai.Berdasarkan teori dan fakta dapat disimpulkan bahwa semakin baik pola asuh yang diterapkan oleh orang tua maka semakin baik pula perkembangan anaknya.Hal ini membuktikan bahwa ada hubungan pola asuh orang tua dengan perkembangan anak. Dengan demikian menjadi hak dan kewajiban orang tua sebagai penanggung jawab yang utama dalam mendidik anakanaknya harus mampu memilih pola asuh yang sesuai bagi anak - anaknya agar masa depan anak menjadi baik seperti yang diharapkan.

\section{KESIMPULAN}

Dari penelitian tentang "hubungan pola asuh orang tua dengan perkembangan anak usia prasekolah di TK RA Cut Nyak Dien Desa Gendingan Kecamatan Kedungwaru kabupaten Tulungagung Tahun 2018", didapatkan hasil adanya hubungan yang signifikan antara pola asuh orang tua terhadap perkembangan anak usia prasekolah. Dimana orang tua yang memiliki pola asuh otoritatif maka perkembangan anak akan sesuai dengan usianya. Dengan pola asuh otoritatif anak merasa meliki tanggung jawab pada dirinya sendiri, kemudian anak juga mempunyai kebebasan untuk memilih apa yang menjadi keinginannya tanpa melupakan peran orang tua sebagai pengontrol dan pembimbing bagi mereka.

\section{UCAPAN TERIMA KASIH}

Terima kasih yang sebesar-besarnya disampaikan kepada pihak TK RA Cut Nyak Dien Desa Gendingan Kecamatan Kedungwaru Kabupaten Tulungagung yang telah memberikan kesempatan kepada peneliti untuk dapat melakukan penelitian tentang pola asuh orang tua.

\section{DAFTAR PUSTAKA}

1. Suherman. Buku Saku Perkembangan Anak. Jakarta: EGC; 1999.

2. Suriviana. Sesuaikah Tumbuh Kembang Anak Anda? 2008.

3. Notoadmodjo S. Promosi Kesehatan dan Perilaku Kesehatan. Jakarta: Rineka Cipta; 2012.

4. Jelsoft. Jumlah Penduduk Indonesia. 2007.

5. UNICEF. The State of the World' s Children 2002 Leadership. Children. United Nations; 2002.

6. Kartono Kartini. Psikologi Anak. Bandung: Mandar Maju; 2007.

7. Wong DL. Buku Ajar Keperawatan. Pediatric. Jakarta: EGC; 2010.

8. Gunarsa SD. Psikologi Anak: Psikologi Perkembangan Anak dan Remaja. Jakarta: PT BPK Gunung Mulia; 2008.

9. Depkes RI. Pedoman Stimulasi, Deteksi Dini dan Intervensi Dini Tumbuh kembang Balita. Jakarta: Depkes RI; 2005. 
10. Soetjiningsih. Tumbuh Kembang Anak. Jakarta: EGC; 2003.

11. Fathi. Pola Asuh dalam Keluarga. 2003.

12. Mutiah D. Psikologi Bermain Anak Usia Dini. Jakarta: Kencana Prenada Media Group; 2010.

13. Landry SH. The role of parents in early childhood learning. Encycl Early Child Dev [Internet]. 2014;1-6. Available from: http://www.child- encyclopedia.com/parenting-skills/accordingexperts/role-parents-early-childhood-learning

14. Dhooria GS, Singh HP, Bhat D, Bains HS, Soni RK, Kumar M. Multidimensional impact on families of children with steroid-sensitive nephrotic syndrome. J Paediatr Child Health [Internet]. 2017 Apr 1 [cited 2018 Mar 7];53(4):354-7. Available from: 